\title{
Optimization of Pressure and Soaking Time of HIP Treatment on 713LC Cast Superalloy
}

\author{
Shih-Hsien Chang* \\ Department of Materials and Mineral Resources Engineering, National Taipei University of Technology, \\ Taipei, 106, Taiwan, R. O. China
}

This paper discusses the effect of pressure and soaking time of HIP on 713LC cast superalloy. In this study, the HIP temperature was kept at $1453 \mathrm{~K}$. Two different pressures, 150 and $175 \mathrm{MPa}$, were applied, and the soaking times were 2 and $4 \mathrm{~h}$. The results of the experiment showed that the HIP treatment for 713LC superalloy at the temperature of $1453 \mathrm{~K}$, pressure of $175 \mathrm{MPa}$, and soaking time of $2 \mathrm{~h}$ yielded the optimal results. Porosity was decreased to $60.3 \%$. At fast strain rate $\left(0.001 \mathrm{~s}^{-1}\right)$, it increased the tensile strength by $8.8 \%$ at $298 \mathrm{~K}, 13 \%$ at $813 \mathrm{~K}$, and $13.6 \%$ at $923 \mathrm{~K}$. The elongation increased $32.9 \%$ at $298 \mathrm{~K}, 21.6 \%$ at $813 \mathrm{~K}$, and $99.5 \%$ at $923 \mathrm{~K}$ in the tension tests. The treatment also increased the strength by $10 \%$ at $298 \mathrm{~K}$ and $17 \%$ at $813 \mathrm{~K}$ in the bending test. HIP treatment was proven to enhance the MC carbide precipitation on grain boundary, improve the grain size and the uniformity of size, and decrease the segregation phenomenon of 713LC casting. [doi:10.2320/matertrans.MER2008435]

(Received November 28, 2008; Accepted February 3, 2009; Published March 25, 2009)

Keywords: hot isostatic pressing (HIP), 713LC cast superalloy, porosity, tensile strength, elongation

\section{Introduction}

Hot Isostatic Pressing (HIP) is a process that uniquely combines higher pressure and temperature to produce materials and parts with substantially better properties than those by other methods. Investigations conducted on several classes of materials showed that HIP could have significant improvements on mechanical properties. ${ }^{1,2)}$ It is widely used on metals because of its advantages of eliminating defect in superalloy castings or large sintered cemented carbide parts. However, its major application is for eliminating casting defects, and it has been widely used in the casting industry to remove the internal porosity generated during the casting process. $^{2-4)}$

Superalloys develop respond to the need for materials with creep and fatigue resistance at high temperature. Ni-based superalloys are used in gas turbine for both aircraft and power generation. ${ }^{5,6)} 713 \mathrm{LC}$ is a cast nickel base precipitation hardened alloy that combines superior cast ability and creep resistance. Owing to its excellent high temperature properties, it has the advantage of wide industrial experience in conventional turbine. ${ }^{7,8)}$ Moreover, 713LC is a $\gamma^{\prime}$ precipitation-strengthened of Ni-based superalloy. The Ni-Cr-Al based superalloys strengthened by the dispersion of coherent $\gamma^{\prime}$ phase belong among the typical precipitation strengthened superalloys. Principal mechanism is precipitation strengthening by coherent precipitates of Inter.-metallic phase $\mathrm{Ni}_{3} \mathrm{Al}$ or $\mathrm{Ni}_{3}$ (Ti, Al). ${ }^{9-12)}$

Several advanced melting and casting techniques have been developed for the superalloy, but the melt related problems such as segregation, porosity and laves phase may lead to degradation of the mechanical properties of the alloy. HIP is one of the most useful techniques to eliminate and improve the defects of superalloy. ${ }^{3)}$ The focus of this study was the improvement of HIP on 713LC cast superalloy. Tension and bending tests on mechanical properties of

*Corresponding author, E-mail: changsh@ntut.edu.tw
713LC castings were conducted at room temperature and high temperature. Porosity tests, X-ray diffraction and microstructure inspections were used to evaluate the effects of HIP treatment at different pressures and soaking times on 713LC cast superalloy.

\section{Experimental}

In this study, the chemical composition (mass\%) of the HIP treated for 713LC cast superalloy is as follows: $75.23 \%$ $\mathrm{Ni}, 11.89 \% \mathrm{Cr}, 4.63 \% \mathrm{Mo}, 1.98 \% \mathrm{Nb}, 5.37 \% \mathrm{Al}, 0.78 \% \mathrm{Ti}$, $0.03 \% \mathrm{Fe}, 0.02 \% \mathrm{Mn}, 0.05 \% \mathrm{C}, 0.01 \% \mathrm{~V}, 0.01 \% \mathrm{Cu}$. The alloys were prepared by vacuum induction melting. After melting, the alloy was solidified into square plate castings. All the specimens of tension test obtain from the castings by WEDM (wire electrical discharge machining). The specimen sizes of the tension (CNS 2112 G2014) and bending (CNS 3940 G2033) tests are shown in Fig. 1. For the tension and bending tests, a SHIMADZU universal material test machine with a maximum load of 25 tons was used.

The key parameters of HIP process include: temperature, pressure, and soaking time. In earlier study, Chang et al. studied the effects of HIP on Inconel 718 superalloy, and found the optimal HIP temperature to be $1453 \mathrm{~K}$ for $713 \mathrm{LC}$ superalloy. ${ }^{13)}$ This study applied the HIP treatment at a temperature of $1453 \mathrm{~K}$ and soaking time of $2 \mathrm{~h}$, with two
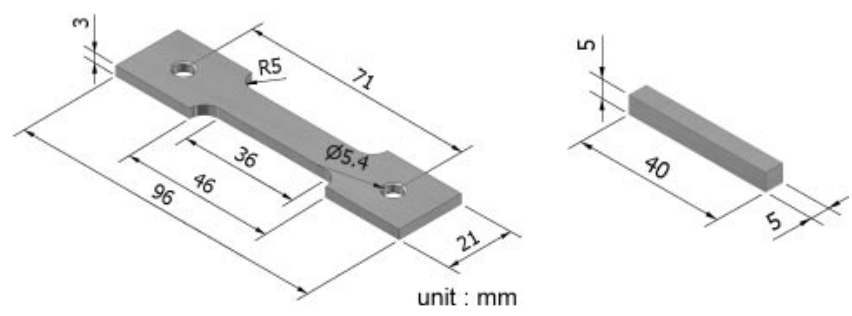

Fig. 1 The specimen size of tension and bending tests for $713 \mathrm{LC}$ superalloy. 
(a)

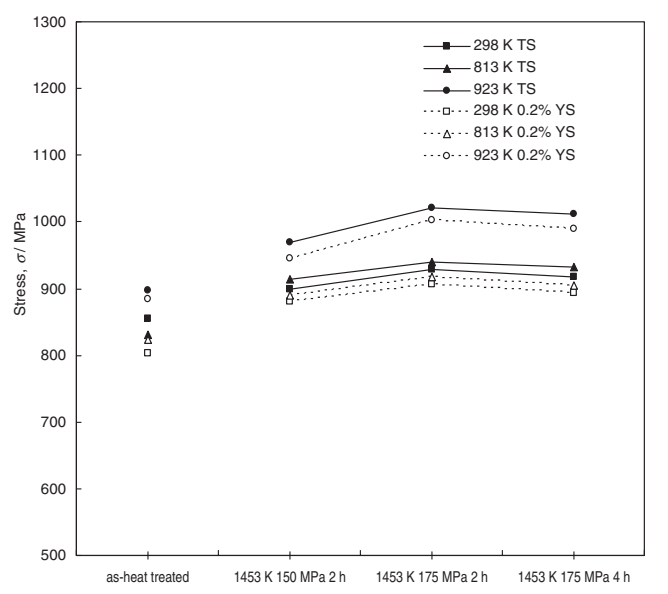

(b)

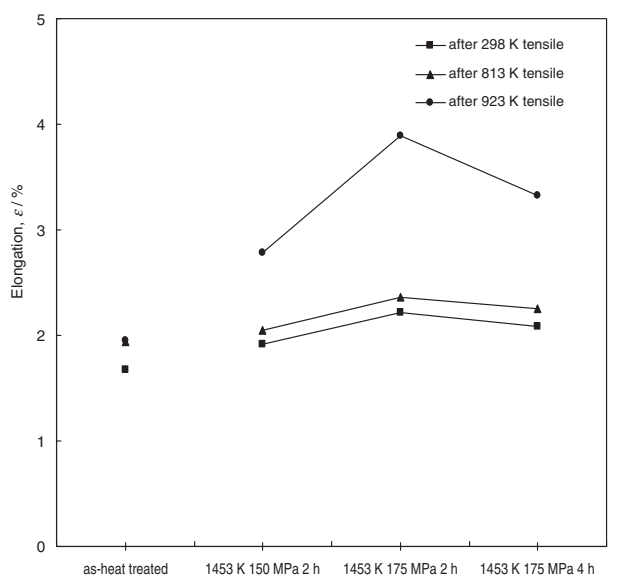

Fig. 2 Comparison of the tensile stress and elongation of as-heat treated and after HIP treatment under different pressure and soaking times for 713LC superalloy (strain rate $=0.001 \mathrm{~s}^{-1}$ ), (a) tensile strength and $0.2 \%$ yield strength; (b) elongation.

different pressures (150 MPa and $175 \mathrm{MPa})$ for $713 \mathrm{LC}$, in order to determine the optimal pressure of HIP treatment. Finally, the temperature and pressure were fixed and the soaking time of HIP process was varied to determine the best soaking time of HIP process.

HIP equipment was from Flow Autoclave Pressure System, Inc. This commercial HIP equipment contains an Uniform Rapid Cooling (URC) system that offers uniform rapid cooling, decreased cycle time, and higher productivity. ${ }^{14,15)}$ After HIP treatment, all the specimens were subjected to the following heat treatment: solution was treated at a temperature of $1448 \mathrm{~K}$ for $2 \mathrm{~h}$, followed by $\mathrm{N}_{2}$ cooling, aged at $923 \mathrm{~K}$ for $16 \mathrm{~h}$, and then air cooled to room temperature. ${ }^{16)}$ The solution-treating and age-hardening processes were performed in a commercial Germanic SCHMETZ vacuum furnace. To evaluate the effects of mechanical properties of 713LC by HIP process, tensile and bending tests at room and high temperature were evaluated. The microstructure, porosity, and XRD inspections were performed.

\section{Results and Discussion}

Chang et al. reported that the main effects on the mechanical properties of nickel-based alloy are segregation and porosity that are formed during casting. Most of the nickel-based superalloys used vacuum melting in production, but the segregation, porosity, and non-uniformity of the microstructure were generated during solidification., ${ }^{3,13}$ Figure 2 shows the tensile strength, $0.2 \%$ yield strength and elongation measured at 298, 813 and $923 \mathrm{~K}$ for $713 \mathrm{LC}$, after HIP treatments. The strain rate of $0.001 \mathrm{~s}^{-1}$ was used. By enhancing the HIP pressure, the tensile strength, $0.2 \%$ yield strength and elongation were increased, but decreased when the HIP soaking time reached $4 \mathrm{~h}$.

The maximum tensile strength, $0.2 \%$ yield strength, and elongation were reached after HIP treatment for $713 \mathrm{LC}$ at $1453 \mathrm{~K}, 175 \mathrm{MPa}$, and $2 \mathrm{~h}$. It significantly increased the tensile strength by $8.8 \%$ at $298 \mathrm{~K}, 13 \%$ at $813 \mathrm{~K}$, and $13.6 \%$ at $923 \mathrm{~K}$. The elongation increased $32.9 \%$ at $298 \mathrm{~K}, 21.6 \%$ at $813 \mathrm{~K}$, and $99.5 \%$ at $923 \mathrm{~K}$ in the tension tests. Particularly the elongation was increased to $99.5 \%$ after $923 \mathrm{~K}$ tension test. When exposed to high temperatures and stresses, the creep property is primary concern in superalloys. However, 713LC has the excellent high temperature creep properties and thermal stability. ${ }^{7,10)}$ It showed that 713LC has a better material strength and ductility under higher temperature, which explains why the 713LC is better suited for a long time high-temperature operating condition than other nickel-based superalloys. The $0.2 \%$ yield strength increased $12.8 \%$ at $298 \mathrm{~K}, 11.4 \%$ at $813 \mathrm{~K}$, and $13.5 \%$ at $923 \mathrm{~K}$. Increasing the HIP pressure could help to reduce the porosity, and enhance the mechanical strength of materials.

Figure 3 shows the similar result, but with a strain rate of $0.0001 \mathrm{~s}^{-1}$ and the test temperatures of $298 \mathrm{~K}$ and $813 \mathrm{~K}$. Increasing the HIP pressure (150 to $175 \mathrm{MPa})$, the slower strain rate showed obvious increase of the tensile strength in $713 \mathrm{LC}$. The tensile strength increased $12.2 \%$ at $298 \mathrm{~K}$ and $10.1 \%$ at $813 \mathrm{~K}$ after optimal HIP treatment. The $0.2 \%$ yield strength increased $15.5 \%$ at $298 \mathrm{~K}$ and $9.6 \%$ at $813 \mathrm{~K}$. By increasing the soaking time of HIP treatment ( 2 to $4 \mathrm{~h}$ ), both the strength and elongation decreased slowly. In fact, all the specimens underwent the solution treatment (1448 K, $2 \mathrm{~h}$ ) after HIP treatment, the temperature was very close to the HIP temperature of $1453 \mathrm{~K}$. The mechanical strength of material was easy to reduce under a long period of high temperature and pressure treatment, which resulted in coarse grains. Therefore, extending the soaking time of HIP treatment is not helpful to enhance the strength of 713LC. The experimental results showed that the HIP treatment for $713 \mathrm{LC}$ castings at $1453 \mathrm{~K}, 175 \mathrm{MPa}$, and for $2 \mathrm{~h}$ was optimal.

The hardness of as-heat treated 713LC casting after solutionized and aged treatments were HRC 39.7. After HIP treatment at $1453 \mathrm{~K}, 175 \mathrm{MPa}$, and for $2 \mathrm{~h}$, the hardness of 713LC reached HRC 40.5. Even after tension test at a temperature of $923 \mathrm{~K}$, the hardness of HIP-ed sample slowly increased to HRC 40.7, as shown in Fig. 4. Increasing the HIP pressure could enhance the solution and precipitation of alloy, thus increasing the hardness of 713LC. However, under the same pressure, increasing the soaking time would decrease the hardness of 713LC. 
(a)

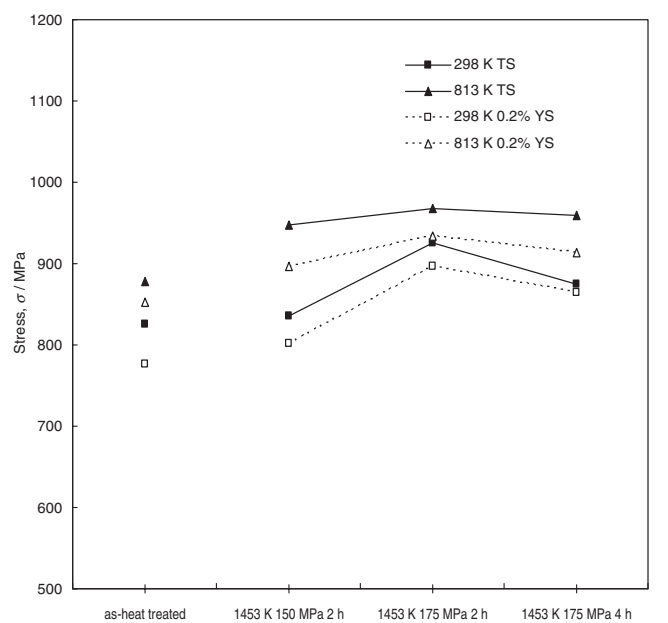

(b)

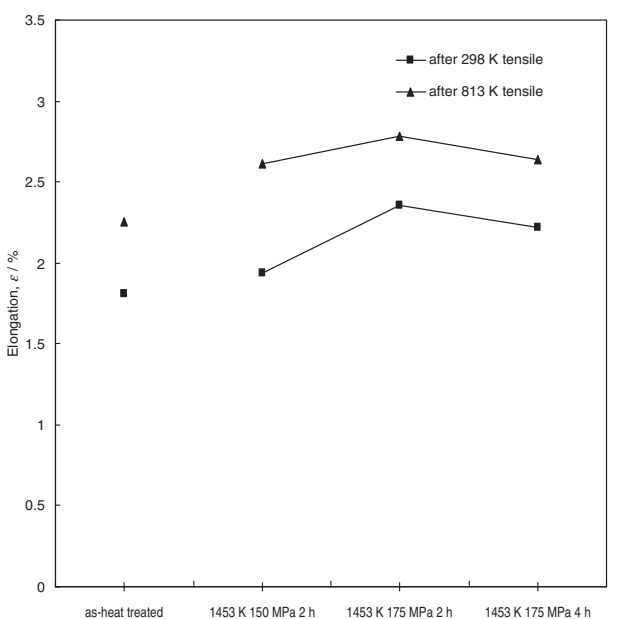

Fig. 3 Comparison of the tensile stress and elongation of as-heat treated and after HIP treatment under different pressure and soaking times for 713LC superalloy ( strain rate $=0.0001 \mathrm{~s}^{-1}$ ), (a) tensile strength and $0.2 \%$ yield strength; (b) elongation.

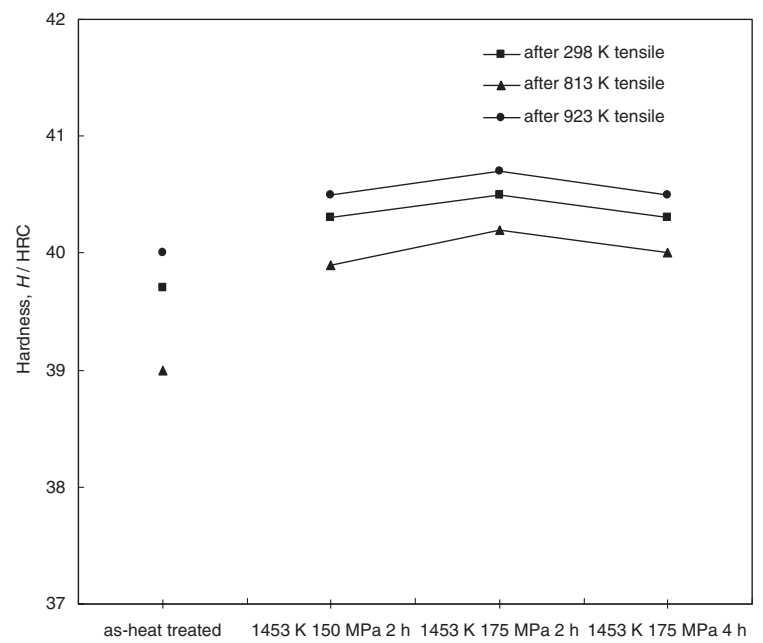

Fig. 4 Comparison of the hardness of as-heat treated and after HIP treatment under different pressure and soaking times for 713LC superalloy ( strain rate $\left.=0.001 \mathrm{~s}^{-1}\right)$.

Figure 5 represents the bending strength of as-heat treated, and after different HIP treatments for 713LC superalloy. The bending rate was kept at $0.005 \mathrm{~s}^{-1}$. Experimental result showed that the bending strength was obviously improved by increasing the pressure and soaking time of HIP treatment. The maximum bending strength appeared after HIP treatment at $1453 \mathrm{~K}, 175 \mathrm{MPa}$, and for $2 \mathrm{~h}$. It enhanced the strength for $10 \%$ at $298 \mathrm{~K}$ and $17 \%$ at $813 \mathrm{~K}$ in the bending test. The results proved that HIP could significantly strengthen the effect of 713LC casting at room and high temperature conditions.

Porosity is a well known cause of inferior mechanical properties in castings. The level of property is strongly related to the shrinkage during solidification. Any increase in porosity reduces fatigue resistance. Elimination of porosity via HIP treatment could improve fatigue and tensile properties. ${ }^{1)}$ Figure 6 shows the porosities of as-heat treated and after different HIP treatments for 713LC. When the soaking time of HIP increased to $4 \mathrm{~h}$, the porosity of casting was very low, at about $0.064 \%$. Due to the HIP

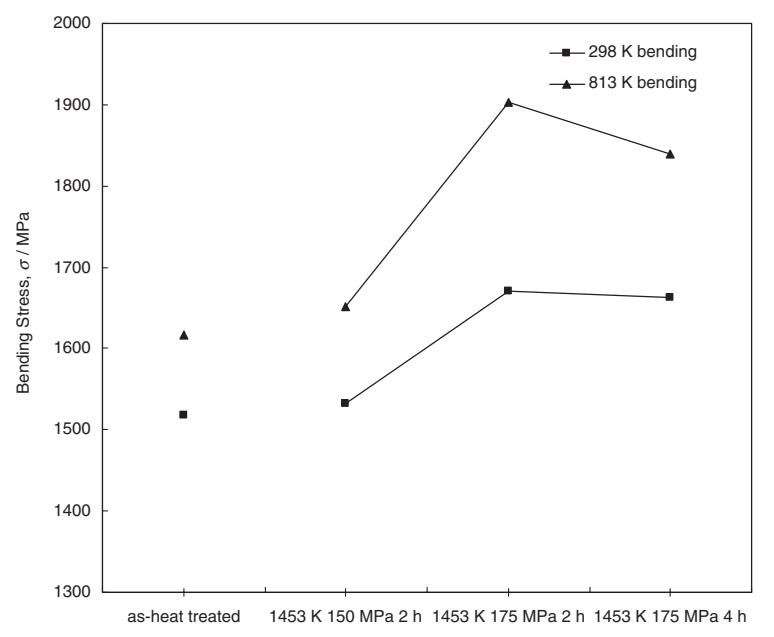

Fig. 5 Comparison of the bending strength of as-heat treated and after HIP treatment under different pressure and soaking times for $713 \mathrm{LC}$ superalloy.

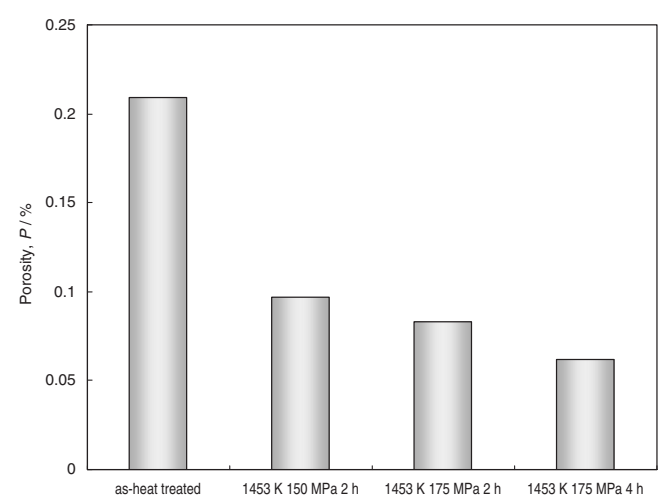

Fig. 6 Comparison of the porosities of as-heat treated and after HIP treatment under different pressure and soaking times for $713 \mathrm{LC}$ superalloy.

treatment combination of pressure and temperature can be used to achieve a particular density at lower temperatures. The effect of the lower temperature is that unacceptable 
grain growth can be avoided, as the high external pressure collapses gas-filled pores and gives full density. The experimental results indicated that by increasing both the pressure and soaking time of HIP treatment, the porosity could be reduced, but the increase in strength of the material was limited.

Figure 7 represents the XRD patterns of as-heat treated and after different HIP treatment for 713LC. After solution $(1448 \mathrm{~K}, 2 \mathrm{~h})$ and aged $(923 \mathrm{~K}, 16 \mathrm{~h})$ treatments, the X-ray diffraction pattern were identified as the $\gamma(111), \gamma(200)$ and $\gamma$ (220) phases of FCC structure. Figures 7(b), 7(c) and 7(d) show the XRD patterns of 713LC after different HIP treatments, the direction of the lattice remained the same. All XRD patterns were identified as the $\gamma(111), \gamma(200)$ and $\gamma$ (220). Comparing between the Figs. 7(b) and 7(c), by increasing the HIP pressure, the intensity of $\gamma$ (111) was obviously decreased, but the $\gamma$ (200) was increased. Furthermore the orientation (220) is preferred. It is also found that by increasing the soaking time of HIP treatment, the preferred orientation of $\gamma$ (220) was replaced by $\gamma(111)$ and $\gamma(200)$ as shown in Fig. 7(d). At the same time, the intensity of $\gamma$ (200) showed an increasing trend.

The optical microstructure of as-heat treated 713LC and after different HIP treatments, solutionized and aged treatments are shown in Fig. 8. It contains a severe segregation and casting microstructure, which is hard to remove from the

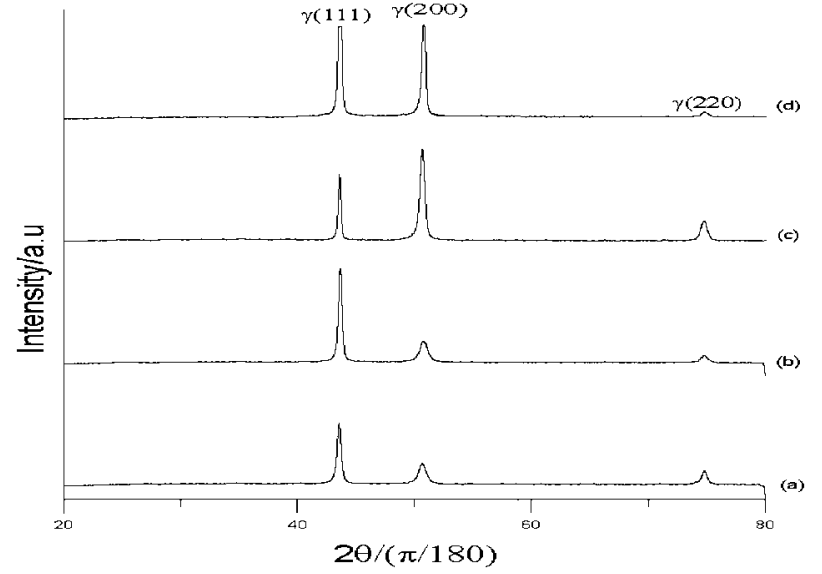

Fig. 7 XRD patterns of as-heat treated and after HIP treatment under different pressure and soaking times for 713LC superalloy, (a) as-heat treated; (b) $1453 \mathrm{~K}, 150 \mathrm{MPa}, 2 \mathrm{~h}$; (c) $1453 \mathrm{~K}, 175 \mathrm{MPa}, 2 \mathrm{~h}$; (d) $1453 \mathrm{~K}$, $175 \mathrm{MPa}, 4 \mathrm{~h}$.

casting structure. Beside, there are a few porosities existing on the microstructure of as-heat treated 713LC casting, as shown in Fig. 8(a). It shows the incomplete solution of the micro-alloy elements of the matrix on precipitation. Figure 8(b) represents the optical microstructures of 713LC after HIP treatment at $1453 \mathrm{~K}, 175 \mathrm{MPa}$, and for $2 \mathrm{~h}$. The
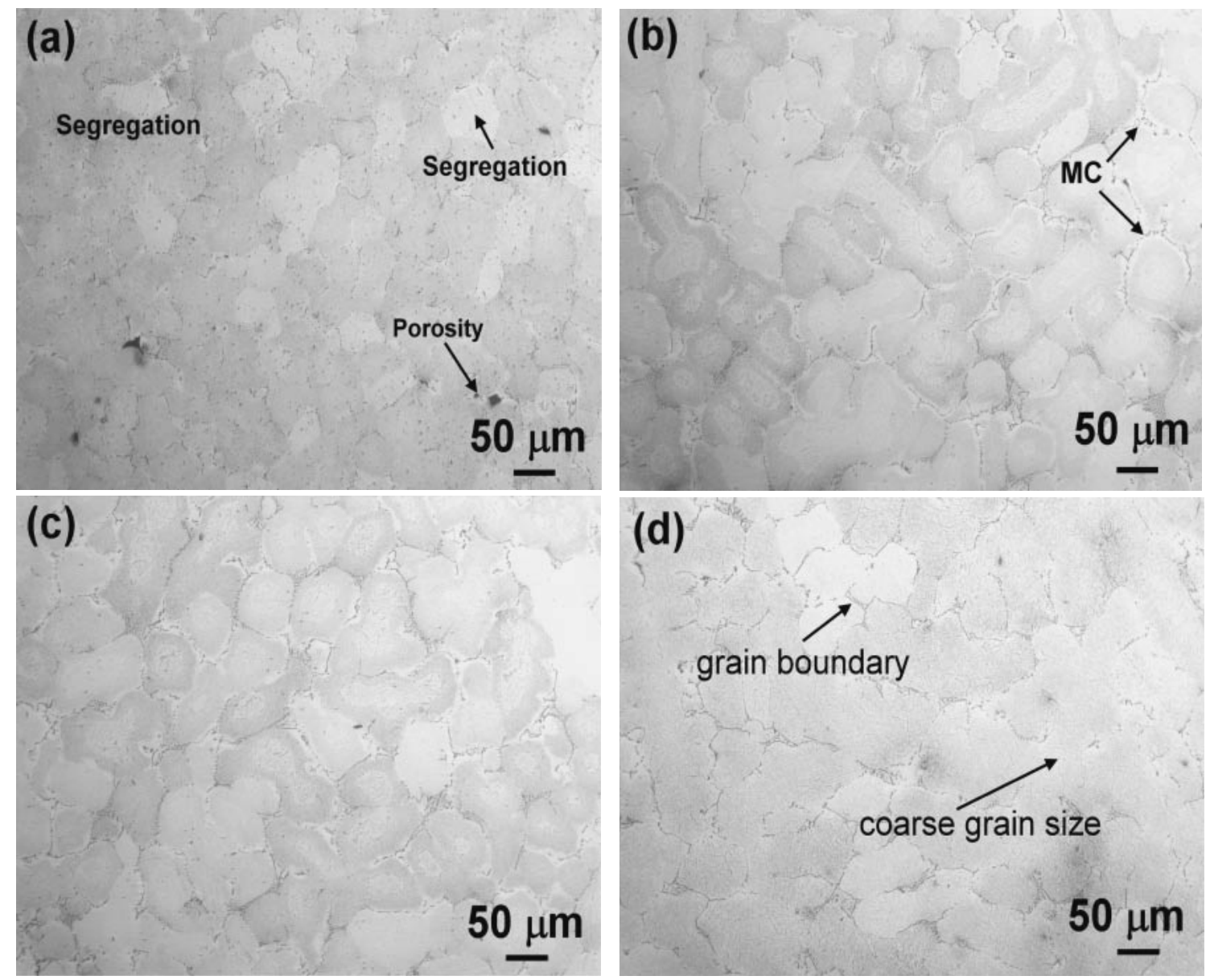

Fig. 8 Optical micrographs of as-heat treated and after HIP treatment under different pressure and soaking times for 713LC superalloy, (a) as-heat treated, (b) $1453 \mathrm{~K}, 150 \mathrm{MPa}, 2 \mathrm{~h}$; (c) $1453 \mathrm{~K}, 175 \mathrm{MPa}, 2 \mathrm{~h}$; (d) $1453 \mathrm{~K}, 175 \mathrm{MPa}, 4 \mathrm{~h}$. 

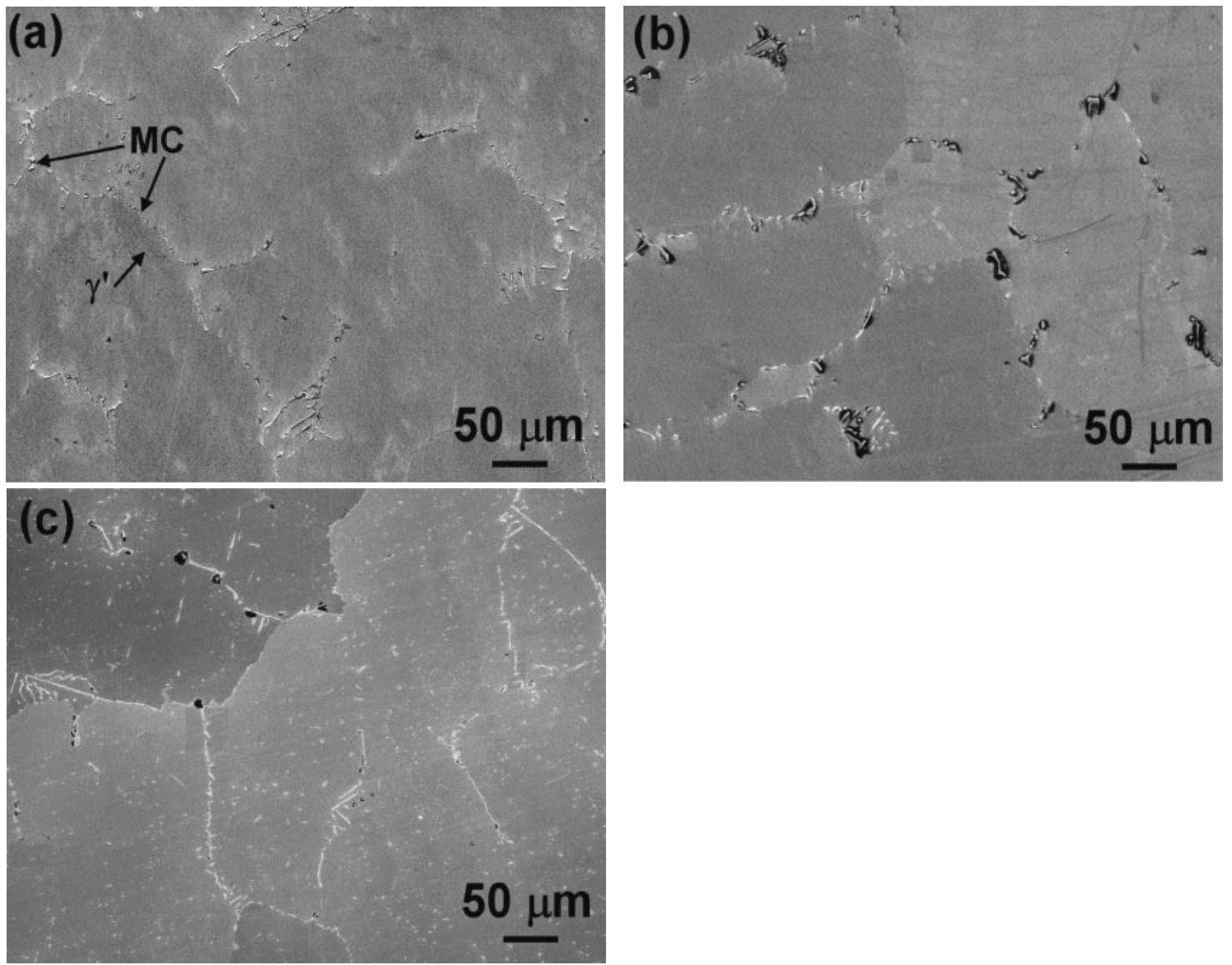

Fig. 9 SEM micrographs of 713LC superalloy after HIP treatment under different pressure and soaking times, (a) $1453 \mathrm{~K}, 150 \mathrm{MPa}, 2 \mathrm{~h}$; (b) $1453 \mathrm{~K}, 175 \mathrm{MPa}, 2 \mathrm{~h}$; (c) $1453 \mathrm{~K}, 175 \mathrm{MPa}, 4 \mathrm{~h}$.

grain sizes were uniform, and the segregated structure was improved. As seen, the grain boundaries were obviously, and the alloying elements of precipitation were more completely. After HIP treatment, the porosity was significantly reduced, as shown in Figs. 8(c) and 8(d). Therefore, this study proved that it could reduce the density of porosity up to $60.3 \%$ after optimal HIP treatment.

Figure 9 is the SEM observation of different HIP treatments for 713LC. Figure 9(a) shows the MC carbide appeared on the grain boundary, and $\gamma^{\prime}$ precipitation on the matrix. As seen, an appropriate increased for both pressure and soaking time not only could enhance the MC carbide precipitation on grain boundary, but also improve the grain size and uniformity of size, as well as the segregation phenomenon of casting. The most common phenomenon is that the $\gamma^{\prime}$ precipitates out first from $\gamma$ matrix. It also could increase the $\gamma^{\prime}$ precipitation to strengthen the effectiveness of precipitation, as shown in Fig. 9(b). The lump MC carbides appeared on the grainboundaries could improve the stress rupture life. Therefore, it proved that the grain-boundaries sliding could be effectively prevented. However, the grains size gradually rose along with the soaking time increase, which would be combined at higher pressure and temperature. Increasing the soaking time of HIP treatment to $4 \mathrm{~h}$, the grain growth resulted in the coarsen microstructure, as shown in Fig. 9(c). The coarsen grain size will lead to the reduction of tensile strength and mechanical properties.
Figure 10 shows the EPMA of matrix for 713LC superalloy after HIP treatment at $1453 \mathrm{~K}, 175 \mathrm{MPa}$, and for $2 \mathrm{~h}$. It is found that most composition of the matrix is $\mathrm{Ni}, \mathrm{Cr}$ and $\mathrm{Al}$ elements. It also presents a much higher content of $\mathrm{Ni}$ element on the matrix. This result suggested that the precipitation should be $\gamma^{\prime}$ of the $\mathrm{Ni}_{3} \mathrm{Al}$ precipitates. ${ }^{9,17)}$ Figure 11 shows the EPMA of precipitation on grain boundary for 713LC after the optimal HIP treatment. The $\mathrm{Ni}$ content substantially reduced, replaced by many alloying elements, such as $\mathrm{Nb}$, Ti and Mo. These elements easily formed $\mathrm{MC}$ metal carbide, leading to strengthening of precipitation effect for 713LC.

\section{Conclusions}

(1) HIP treatment could effectively improve the microstructure and tensile properties of 713LC cast superalloy. The experimental results showed that HIP treatment at $1453 \mathrm{~K}, 175 \mathrm{MPa}, 2 \mathrm{~h}$ is the optimal process. The optimal HIP treatment could decrease the porosity of $713 \mathrm{LC}$ for $60.3 \%$, and enhance the bending strength for $10 \%$ at $298 \mathrm{~K}$ and $17 \%$ at $813 \mathrm{~K}$.

(2) The XRD patterns of 713LC after different HIP treatments, the direction of the lattice remained the same. All XRD patterns were identified as the $\gamma(111), \gamma$ (200) and $\gamma$ (220). Increasing the soaking time of HIP treatment, the preferred orientation of $\gamma$ (220) was replaced by $\gamma$ (111) and $\gamma(200)$. 


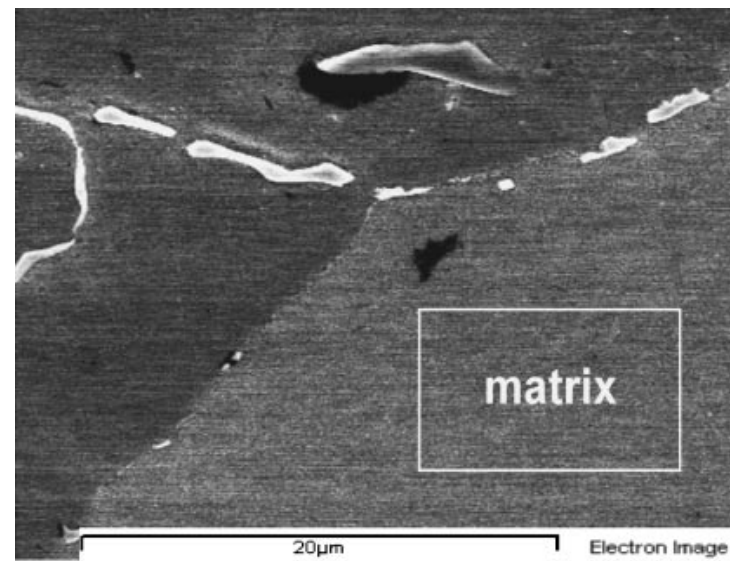

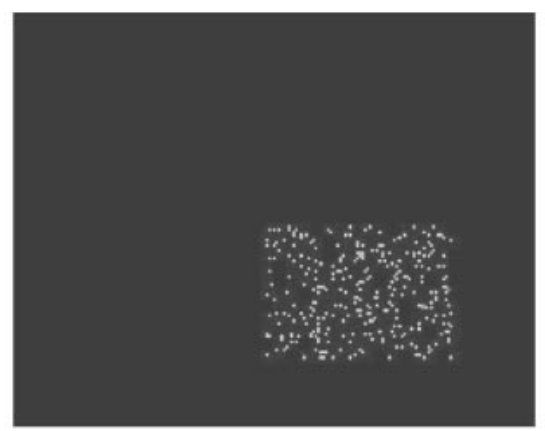

Chromium Ka1

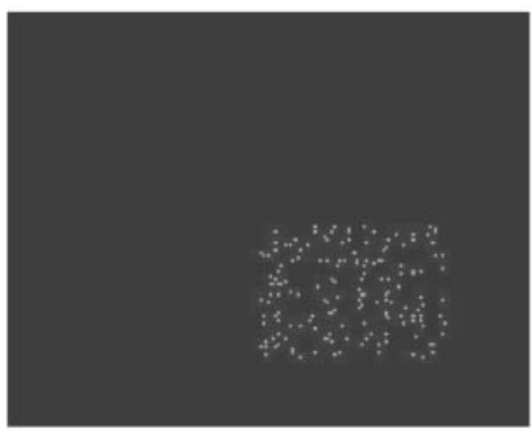

Aluminum Ka1

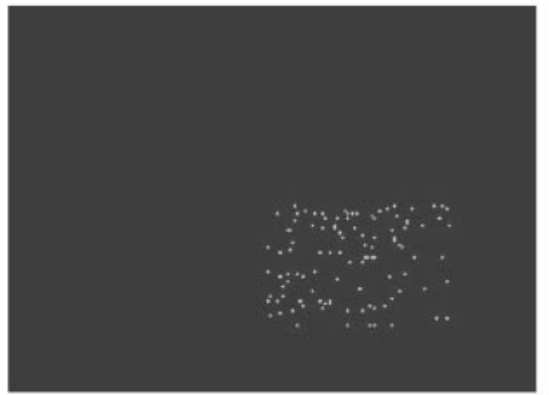

Molybdenum La1

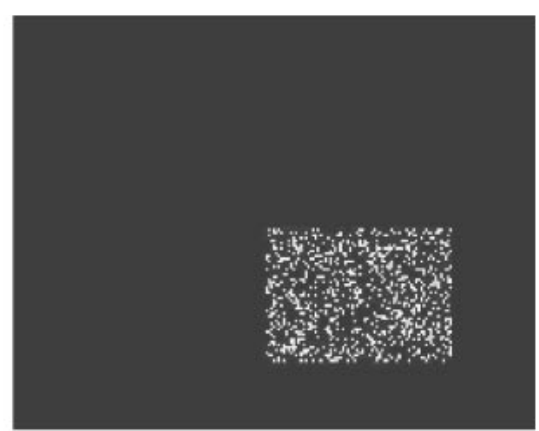

Nickel Ka1

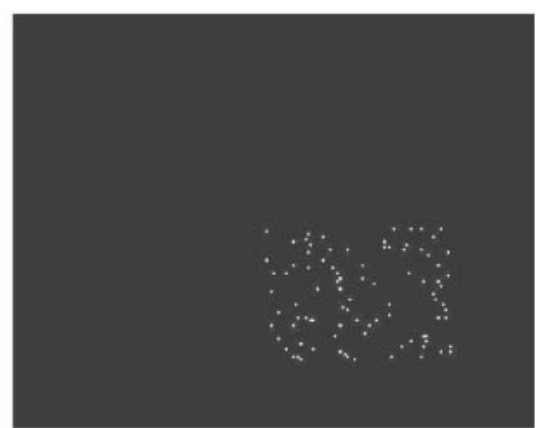

Niobium La1

Fig. 10 EPMA results of matrix for 713LC superalloy after $1453 \mathrm{~K}, 175 \mathrm{MPa}, 2 \mathrm{~h}$ HIP treatment.

(3) The MC carbide appeared on the grain boundary and $\gamma^{\prime}$ precipitation on the matrix of 713LC after HIP treatment. It shows the precipitation should be $\gamma^{\prime}$ of the $\mathrm{Ni}_{3} \mathrm{Al}$ precipitates. By the optimal HIP treatment, the grain sizes were uniform and the segregated structure was improved.

\section{Acknowledgments}

This research supported by the Materials and ElectroOptics Research Division of Chung-Shan Institute of Science and Technology Taiwan. The author would also like to express his appreciation for Professor S. C. Lee. 


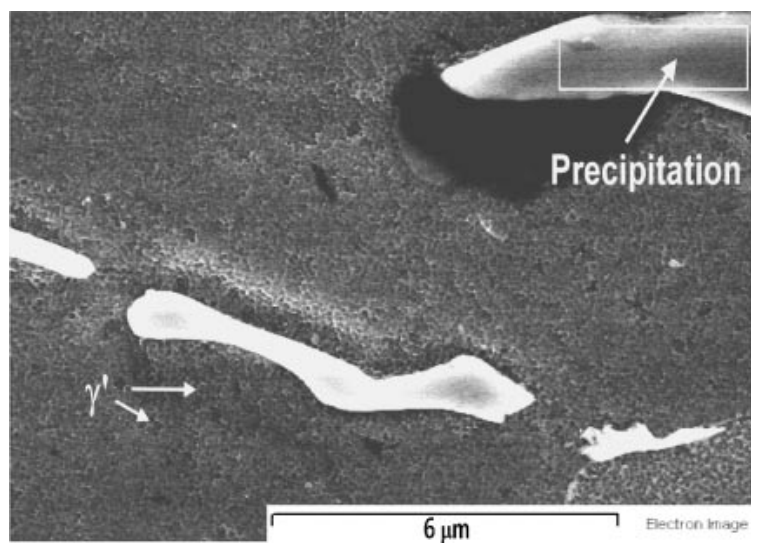

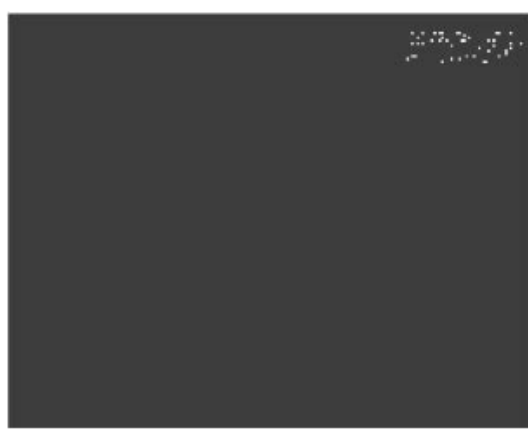

Nickel Ka1

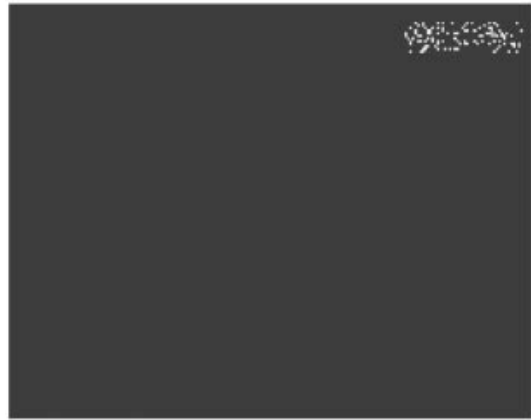

Titanium Ka1

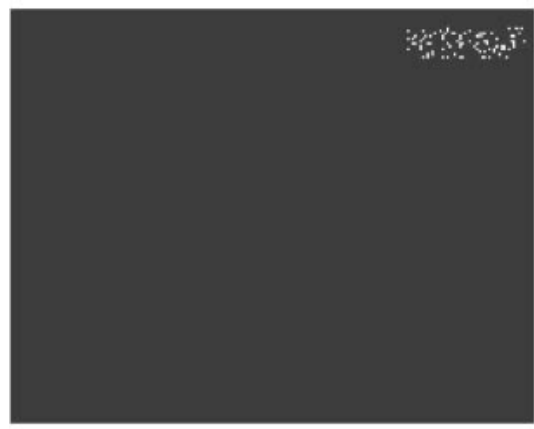

Molybdenum La1

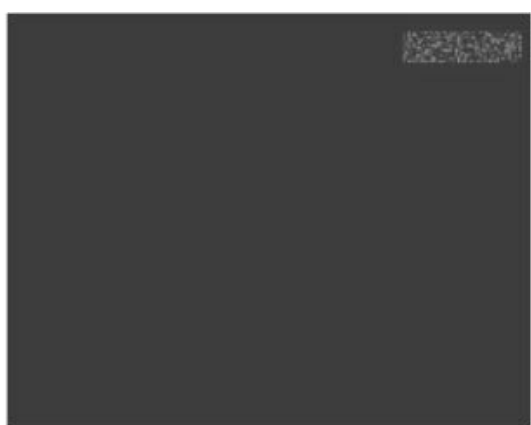

Niobium La1

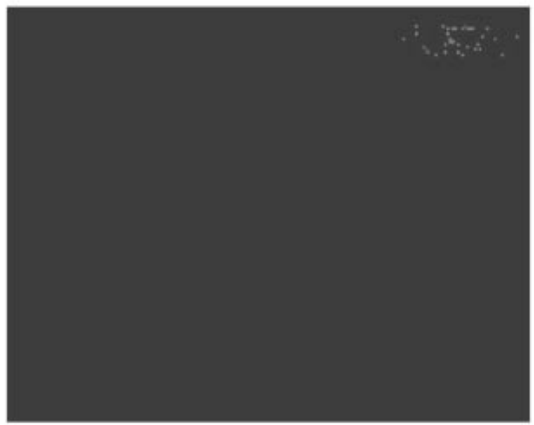

Aluminum Ka1

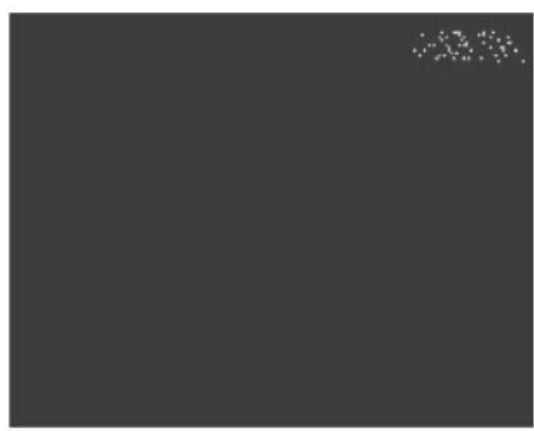

Chromium Ka1

Fig. 11 EPMA results of precipitation on grain boundary for 713LC superalloy after $1453 \mathrm{~K}, 175 \mathrm{MPa}, 2 \mathrm{~h}$ HIP treatment.

\section{REFERENCES}

1) C. Barre: Int. J. Powder Metall. 35 (1999) 51-52.

2) T. Garvare: Proc. Int. Conf. on Hot Isostatic Pressing-Lulea/15-17 June, (The Swedish Institute of Production Engineering Research, 1987) pp. 3-89.

3) S. C. Lee, S. H. Chang, T. P. Tang, H. H. Ho and J. K. Chen: Mater.
Trans. 47 (2006) 2877-2881.

4) M. Koizumi: Hot Isostatic Pressing Theory and Applications, Int. Conf. on Hot Isostatic Pressing, (Elsevier Applied Science, 1992) pp. 11-187.

5) F. A. Souza, F. M. Bastos and P. R. M. Jorge: Thermal Eng. 3 (2004) $115-121$.

6) Z. Li and K. C. Mills: Metall. Mater. Trans. B 37B (2006) 781-790. 
7) I. S. Kim, B. G. Choi, S. M. Seo and C. Y. Jo: Met. Mater. Int. 12 (2006) $1-5$.

8) T. Podrabsky, Z. Jonsta, K. Hrbacek and K. Nemec: Acta Metall. Slovaca. 9 (2003) 198-202.

9) Z. Jonsta, P. Jonsta, V. Vodarek and K. Mazanec: Acta Metall. Slovaca. 13 (2007) 546-553.

10) R. R. Bowman and S. D. Antolovich: Metall. Trans. A 17A (1986) 173180.

11) T. Podrabsky, M. Julis, S. Pospisilova, K. Nemec, K. Hrbacek, A. Rek and Z. Jonsta: Acta Metall. Slovaca. 11 (2005) 62-67.

12) Donachie and Matthew J: Superalloys-A Technical Guide, (ASM
Inter. 1988) pp. 15-124.

13) S. H. Chang, S. C. Lee, T. P. Tang and H. H. Ho: Mater. Trans. 47 (2006) 426-432.

14) Flow Autoclave System, Inc.: Hot Isostatic Pressing Applications (1996).

15) F. Zimmerman, C. Bergman and J. Westerlund: Int. J. Powder Metall. 35 (1999) 31-35.

16) S. S. Manson: Nonferrous alloys 713LC, code 4108, (Aerospace Structure Metal Handbook, 1976) pp. 1-22.

17) Z. Jonsta, P. Jonsta, J. Sojka and V. Vodarek: Acta Metall. Slovaca. 12 (2006) 436-442. 